\title{
Public knowledge and attitudes towards Human Papilloma Virus (HPV) vaccination
}

\author{
Charlotte Devereaux Walsh², Aradhana Gera², Meeraj Shah², Amit Sharma², \\ Judy E Powell ${ }^{3}$ and Sue Wilson*1
}

Address: ${ }^{1}$ Department of Primary Care and General Practice, Division of Primary Care, Public and Occupational Health, The University of Birmingham, Birmingham B15 2TT, UK, 2The Medical School, The University of Birmingham, University of Birmingham, Birmingham B15 2TT, UK and ${ }^{3}$ Department of Public Health, Division of Public Health and Epidemiology, The University of Birmingham, Birmingham B15 2TT, UK

Email: Charlotte Devereaux Walsh - CRD478@bham.ac.uk; Aradhana Gera - AXG370@bham.ac.uk; Meeraj Shah - MXS409@bham.ac.uk; Amit Sharma - AXS410@bham.ac.uk; Judy E Powell - j.e.powell@bham.ac.uk; Sue Wilson* - s.wilson@bham.ac.uk

* Corresponding author

Published: 23 October 2008

BMC Public Health 2008, 8:368 doi:10.1 186/147/-2458-8-368
Received: 16 January 2008

Accepted: 23 October 2008

This article is available from: http://www.biomedcentral.com//47/-2458/8/368

(c) 2008 Walsh et al; licensee BioMed Central Ltd.

This is an Open Access article distributed under the terms of the Creative Commons Attribution License (http://creativecommons.org/licenses/by/2.0), which permits unrestricted use, distribution, and reproduction in any medium, provided the original work is properly cited.

\begin{abstract}
Background: Human Papilloma Virus (HPV) vaccine has undergone successful trials and has recently been approved for use for the primary prevention of cervical cancer. The aim of this study was to determine knowledge and attitudes towards HPV vaccination.
\end{abstract}

Methods: Semi-structured interview and questionnaire delivered in a street survey. Standardised HPV-related statements used to measure HPV knowledge and attitudes to vaccination. The setting was three different areas of Birmingham, to target a mix of social class and ethnicity. The sample population was composed of 16-54 year olds.

Results: A total of 420 participants were recruited. Poor knowledge of HPV and its links with cervical cancer were observed. $81 \%$ had a knowledge score of zero. Knowledge about HPV was associated with different ethnic group and socio-economic group. The majority $(88 \%)$ of participants were in favour of vaccination, with $83.6 \%$ indicating that they would allow a child under their care to be vaccinated.

Conclusion: Initial responses to the proposed HPV vaccination within the UK public are favourable. However, knowledge levels are poor and media and health professional promotion are required to raise awareness.

\section{Background}

Since the 1970's it has been known that one of the causes of cervical cancer is through infection with Human Papilloma Virus (HPV) [1] subtypes of HPV causing malignant transformation of the cervical epithelium [1,2]. This breakthrough led to the possibility that some cervical cancers could be preventable by vaccination $[1,2]$. There are approximately one hundred different genotypes of HPV. [3] Forty of these types infect the genitalia, and fifteen put women at a high risk of cervical cancer $[3,4]$. In the UK and many other countries, HPV-16 and 18 are the most common subtypes associated with cervical carcinoma and are believed to be implicated in the aetiology of $70 \%$ of malignancies $[2,3]$. 
An HPV vaccine has been developed by two separate drug companies: Merck, which produces Gardasil, and GlaxoSmithKline, which produces Cervarix [5]. Both drugs have undergone phase III trials, and were approved for use in the USA in 2006, the Merck vaccine was also approved for use in the UK in 2006 [1,6-10]. To maximise effectiveness, the vaccine needs to be given to girls before they are sexually active [11]. Initial discussions for a UK vaccination programme suggested targeting girls aged 10-12 years [12]. On 26th October 2007, the Department of Health (England) announced the Government immunisation programme would commence in 2009 with HPV vaccination of girls aged $12-13$ years $[13,14]$.

Despite HPV vaccination being a relatively new concept, there are a number of studies that have discussed the effectiveness of the vaccine and how it works $[6-9,15]$. However, relatively few investigations have addressed the public's support for vaccinating school age children. The majority of the research that has been undertaken has not been based in the UK [16-20] and reports parental (especially maternal) and adolescent attitudes towards HPV vaccination, rather than the attitudes of the general public [19-22].

A Finnish study reported $86 \%$ of parents and adolescents approved of the vaccine [19] and over $90 \%$ of mothers in Vietnam were in favour of their daughters receiving the vaccine although only $1 \%$ had previous awareness of the possibility of vaccination [20]. Such findings are reenforced by a recent review of the literature on HPV vaccine acceptability which reported that many women had a poor knowledge about HPV but, nevertheless, most parents are interested in having their children vaccinated [23].

A Canadian study, published in 2000, assessing public knowledge reported that only $13 \%$ of adolescents had heard about HPV [24], however a more recent study, conducted 2006-07, reported that $70 \%$ of respondents with female children intended to have their daughters vaccinated [25]. A study, in Georgia, undertook 35 focus groups with stratification by gender, race and location. Knowledge, attitude and beliefs about HPV were explored. Low knowledge and the association of the vaccine with STD were concluded to be barriers to future acceptance of the vaccine [26].

The relatively small number of UK based studies undertaken to date also tend to report that people generally know little about HPV, but after the provision of information, most support the introduction of the vaccine [2730]. A recent survey of British women aged 16-97 used an open question to elicit the causes of cervical cancer; only 2.5\% mentioned HPV and 7\% mentioned an unspecified sexually transmitted virus/infection [28]. However, the majority of parents of 11-12 year old school children state that they would allow their child to be vaccinated $[27,30]$ and only a minority express concern that it may encourage unsafe sexual behaviour $[27,30]$. This latter issue has appeared in national newspapers, with one paper leading with the headline "NHS giving out 'promiscuity jab' by the backdoor" [31].

In summary the literature published to date shows low levels of public knowledge about HPV and its links to cervical cancer. However, the majority of studies also show that people are generally in favour of vaccination.

This study aimed to determine public awareness of, and attitudes towards, HPV vaccination in three urban areas of Birmingham. Secondary aims were to determine the effect of social class and ethnicity on attitudes towards the proposed vaccine. A better understanding of factors that may be associated with low knowledge or negative attitudes to screening being important to inform the targeting of future awareness campaigns.

\section{Methods \\ Settings/Study Population}

Participants were recruited from the Birmingham area of the United Kingdom during period April-May 2007. The Birmingham conurbation has a $66 \%$ White British population, compared with a national average of $87 \%$ [32]. Ethnic minority groups (excluding White Irish) make up $29.6 \%$ of the population compared with the national average of $7.9 \%$. These ethnic groups (in order of size) comprise Pakistani, Indian, Black Caribbean, mixed races, Bangladeshi, and smaller groups such as Chinese and Black Africans.

To ensure a range of participants were recruited, data collection was conducted in three areas of Birmingham (Northfield - predominantly White, British, Ladywood relatively high proportion of ethnic minorities, Sutton Coldfield - population generally of a higher social class compared to the other two areas), which were purposively chosen to reflect the diversity of social class and ethnicity across the city.

\section{Data collection}

This cross-sectional survey was conducted as a street survey. Members of the public were recruited to participate in a semi-structured interview using flash cards as prompts for the collection of categorical data. The main street of each area was used to ensure access to a large and varied selection of people. All interviews were conducted by four medical students. Practice interviews were conducted before the commencement of data collection to ensure 
that interviews were undertaken in a standardised manner.

Purposive sampling was used to ensure the inclusion of sufficient subjects in each sub-group of interest (age, gender, socio-economic group, ethnicity). The composition of the study sample was predetermined and aimed to recruit adults (aged 16-54 years) in the following proportions: white $70 \%$, ethnic minorities 30\%; three geographical locations: $33.3 \%$ each; non manual workers (social classes $1-3 \mathrm{~N}$ ) 50\%, manual workers (social classes 3M-5) $50 \%$; male 50\%, female 50\%; age bands, 16-24, 25-34, 35-55, 45-54, 25\% each).

Balanced groups were obtained by pre-determining the number of people required in each sub-group of interest. After a short introduction about the study, potential participants were first asked their age, then ethnicity and socio-economic group to determine eligibility. If sufficient participants had been recruited to the relevant subgroup, potential participants were thanked for their time and told that sufficient people in this sub-group had already been recruited. Recruitment continued in each of the three geographical areas until sufficient people had been recruited into each strata. Information on the recruitment rate and the characteristics of non-participants were not collected.

Social class was assessed using the Registrar General's Social Scale [33] which has six groups (1: Professional e.g. accountant, Doctor, Lawyer; 2: Intermediate e.g. manager, school teacher, nurse; 3N: Skilled Non-manual e.g. Clerical worker, secretary and shop assistant; 3M: Skilled Manual e.g. Bus driver, Coal-face worker, Carpenter; 4: Semiskilled manual e.g. Agricultural worker, Bus conductor, Postman; 5: Unskilled manual e.g. Labourer, Cleaner, Dock worker). Ethnicity was assessed using the criteria for the UK 2001 Census [34].

A sample size of 383 was pre-specified as being sufficient to determine the proportion of people with a knowledge score of less than 2 with 5\% precision, 90\% power and $95 \%$ confidence [35].

\section{Measurement and Analysis}

Data collected were entered into SPSS V 14.0. Data entry errors were resolved by reference to data collection sheets.

Questionnaire administration commenced with sociodemographic questions, followed by an assessment of HPV knowledge. Therefore, for each respondent, a knowledge score was calculated from six HPV related questions. One point was allocated for each positive ("yes") answer resulting in a score from zero to six [0 (no knowledge) to 6 (high knowledge)]. If the respondent answered "No" to the first of these questions ("Have you heard of HPV?"), then the remaining HPV knowledge questions were not asked. For the purposes of modelling, the knowledge score was reduced to a binary variable (no knowledge: knowledge score $=0$ vs. some knowledge: knowledge score $>0$ ).

The six questions asked comprised:

\section{1) Have you heard about Human Papilloma Virus?}

2) Did you know the Human Papilloma Virus can be transmitted through sexual intercourse?

3) Have you heard about the HPV vaccination?

4) Did you know it is a vaccination which protects women against cervical cancer?

5) Did you know that the government is considering offering HPV vaccination to school girls aged 10-12?

6) Did you know a lot of women have already acquired one or more HPV type(s) covered by the vaccine?

Subsequent to the provision of standardised information (information provided to all participants, irrespective of HPV knowledge score) relating to HPV, attitudes to HPV vaccination were assessed using the question: "Do you think that the introduction of HPV vaccination is a good idea?" A Likert scale ranging from strongly agree (score: 1) to strongly disagree (score: 5) was used. For the purposes of modelling, the attitude score was reduced to a binary variable (negative attitude: no opinion, disagree and strongly disagree, vs. positive attitude: agree and strongly agree). The interview ended with some questions relating to how much people were prepared to pay for vaccination and whether boys should also be vaccinated.

To facilitate modelling, independent variables were dichotomised to: manual (3M-5) vs. non-manual (1-3N), older (age 45+) vs. younger (age <45), white vs. non-white (all ethnic groups other than white British).

A parent was defined as anyone with children regardless of age of the child. Parents were asked to imagine when their child was the target age (10-12 years) and to answer the questions relating to attitudes to vaccination accordingly.

Data were not normally distributed. The Mann Whitney U test (gender, social class, ethnicity, parenthood) and Kruskal-Wallis test (age groups, areas) were used to test for differences between groups in knowledge and attitude scores. Mean knowledge scores are reported in the text, all 
groups of interest having a median score of zero. Binary logistic regression (forward stepwise method) was conducted, using SPPS v14, to explore the effect of variables demonstrated to be significantly associated with the outcomes of interest (knowledge, attitude) in the univariate analyses.

Ethical approval for this study was provided by South Birmingham Research Ethics Committee in November 2006 (ref: S/2006/113).

\section{Results}

One hundred and forty people in each of the three locations were recruited, generating a total sample of 420 (Table 1). Of the 420 people, 315 (75\%) were white and 105 (25\%) ethnic minorities. The non-manual group (social classes I - IIIM) comprised 241 (57.4\%) people with $179(42.6 \%)$ in the manual (social classes IV - V). 159 (37.9\%) participants were male and 261(62.1\%) female. There were 20\%-30\% participants in (each of the four age group bands). Fifty-nine per cent of the 420 participants were parents.

\section{Knowledge Score}

Three hundred and forty $(81 \%, 95 \%$ CI $=76.9 \%$ to $84.6 \%)$ of the study participants had a knowledge score of $0($ mean $=0.51, \mathrm{SD}=1.33$, median $=0)$. Only $25(5.9 \%)$ participants had a score of 4 or more. The proportion of participants with a Knowledge scores of 0-6 varied by subgroup (ethnicity, gender, social class and age) (Table 2).

Significant differences in knowledge scores were observed between ethnic groups (scores $>0$ : $23 \%$ of white and $8.3 \%$ of non-white category); social class (scores $>0: 30.1 \%$ of non-manual and $9.8 \%$ of manual category); with increasing age (scores $>0$ : $16.24=12.7 \%, 25-34=19.8 \%, 35-44$ $=17.5 \%, 45-54=28 \%$ ), and by gender (scores $>0$ : males

Table I: Characteristics of participants

\begin{tabular}{|c|c|c|c|}
\hline & & $\mathbf{N}$ & $\%$ \\
\hline \multicolumn{4}{|l|}{ Area } \\
\hline & Ladywood & 140 & 33.3 \\
\hline & Northfield & 140 & 33.3 \\
\hline & Sutton Coldfield & 140 & 33.3 \\
\hline \multicolumn{4}{|c|}{ Age Group } \\
\hline & $16-24$ & 110 & 26.2 \\
\hline & $25-34$ & 91 & 21.7 \\
\hline & $35-44$ & 126 & 30.0 \\
\hline & $45-54$ & 93 & 22.1 \\
\hline \multicolumn{4}{|c|}{ Gender } \\
\hline & Male & 159 & 37.9 \\
\hline & Female & 261 & 62.1 \\
\hline \multicolumn{4}{|c|}{ Ethnicity } \\
\hline & White British and Irish & 305 & 72.6 \\
\hline & Mixed & 13 & 3.1 \\
\hline & Asian (Indian, Pakistani, Bangladeshi or other) & 54 & 12.9 \\
\hline & Black (Black African, Black Caribbean or other) & 37 & 8.8 \\
\hline & Other (including Chinese) & 11 & 2.6 \\
\hline \multicolumn{4}{|c|}{ Social Class } \\
\hline & I & 9 & 2.1 \\
\hline & $\|$ & 67 & 16.0 \\
\hline & IIIN & 109 & 26.0 \\
\hline & IIIM & 56 & 13.3 \\
\hline & IV & 61 & 14.5 \\
\hline & $\vee$ & 118 & 28.1 \\
\hline \multicolumn{4}{|c|}{ Parents } \\
\hline & Yes & 248 & 59.0 \\
\hline & No & 172 & 41.0 \\
\hline
\end{tabular}


Table 2: Knowledge scores by ethnicity, social class; age and gender

\begin{tabular}{|c|c|c|c|c|c|c|c|c|c|}
\hline & & \multicolumn{5}{|c|}{ KNOWLEDGE SCORE } & \multirow[b]{2}{*}{ Mean score } & \multirow[b]{2}{*}{ SD } & \multirow[b]{2}{*}{$\mathrm{p}$-value* } \\
\hline & & 0 & $\mathbf{I}$ & 2 & $3-4$ & $5-6$ & & & \\
\hline \multicolumn{10}{|l|}{ Ethnicity } \\
\hline \multirow[t]{2}{*}{ White } & $\mathrm{N}$ & 235 & 30 & 13 & 13 & 14 & 0.61 & 1.416 & \\
\hline & $\%$ & 77.0 & 9.8 & 4.3 & 4.3 & 4.6 & & & \\
\hline \multirow[t]{2}{*}{ Non-White } & $\mathrm{N}$ & 105 & 4 & I & 2 & 3 & 0.26 & 1.035 & 0.001 \\
\hline & $\%$ & 91.3 & 3.5 & 0.9 & 1.7 & 2.6 & & & \\
\hline \multicolumn{10}{|l|}{ Social Class } \\
\hline \multirow{2}{*}{ Non-manual (I-IIIN) } & $\mathrm{N}$ & 128 & 22 & 8 & 12 & 15 & 0.90 & 1.745 & \\
\hline & $\%$ & 69.2 & 11.9 & 4.3 & 6.5 & 8.1 & & & \\
\hline \multirow[t]{2}{*}{ Manual (IIIM-V) } & $\mathrm{N}$ & 212 & 12 & 6 & 3 & 2 & 0.20 & 0.742 & $<0.001$ \\
\hline & $\%$ & 90.2 & 5.1 & 2.6 & 1.3 & 0.9 & & & \\
\hline \multicolumn{10}{|l|}{ Age } \\
\hline \multirow[t]{2}{*}{$16-24$} & $\mathrm{~N}$ & 96 & 8 & 3 & 2 & $\mathrm{I}$ & 0.25 & 0.826 & \\
\hline & $\%$ & 87.3 & 7.3 & 2.7 & 1.8 & 0.9 & & & \\
\hline \multirow[t]{2}{*}{$24-34$} & $\mathrm{~N}$ & 73 & 9 & 3 & 4 & 2 & 0.44 & 1.128 & \\
\hline & $\%$ & 80.2 & 9.9 & 3.3 & 4.4 & 2.2 & & & \\
\hline \multirow[t]{2}{*}{$34-44$} & $\mathrm{~N}$ & 104 & 7 & 4 & 5 & 6 & 0.52 & 1.390 & \\
\hline & $\%$ & 82.5 & 5.6 & 3.2 & 4.0 & 4.8 & & & \\
\hline \multirow[t]{2}{*}{$44-54$} & $N$ & 67 & 10 & 4 & 4 & 8 & 0.86 & 1.779 & 0.034 \\
\hline & $\%$ & 72.0 & 10.8 & 4.3 & 4.3 & 8.6 & & & \\
\hline \multicolumn{10}{|l|}{ Gender } \\
\hline \multirow[t]{2}{*}{ Male } & $\mathrm{N}$ & 136 & 12 & 3 & 4 & 4 & 0.35 & 1.091 & \\
\hline & $\%$ & 85.5 & 7.5 & 1.9 & 2.5 & 2.5 & & & \\
\hline \multirow[t]{2}{*}{ Female } & $\mathrm{N}$ & 204 & 22 & 11 & 11 & 13 & 0.61 & 1.450 & 0.05 \\
\hline & $\%$ & 78.2 & 8.4 & 4.2 & 4.2 & 5.0 & & & \\
\hline
\end{tabular}

* derived from Kruskall-Wallis test for age; Mann-Whitney $U$ test for other factors

$=14.5 \%$, females $=21.8 \%$ ) (Table 2$)$. No differences in knowledge scores were revealed between parents and those who were not parents (mean scores $=0.58$ and 0.40 respectively) ( $p=0.285)$ or between the three geographical areas surveyed $(\mathrm{p}=0.19)$.

Logistic regression modelling explored the effect of gender, age group, ethnic group and social class on knowledge scores (any knowledge vs. no knowledge). Predictors of having no knowledge were non white ethnicity (adjusted odd ratio $=2.96,95 \% \mathrm{CI} 1.44$ to 6.10 ) and being a manual worker $(\mathrm{OR}=4.10,95 \% \mathrm{CI} 2.39$ to 7.06$)$. Older age (45+ years) resulted in a decreased probability of no knowledge (OR $=0.32,95 \%$ CI 0.30 to 0.96$)$. After including ethnicity, social class and age band in the model, gender was no longer a significant factor.

\section{Attitude towards HPV Vaccination}

Three hundred and seventy (88.1\%, 95\% CI $84.4 \%$ to $90.9 \%$ ) participants agreed or strongly agreed with HPV vaccination, $6 \%$ had no opinion and $6 \%$ disagreed or strongly disagreed. The median score was 2.0 ( $1=$ Strongly Agree, 5 = Strongly Disagree); participants tending to report that they agreed with vaccination. The mean response for attitude for the white ethnic group was 1.88 (Table 3) whereas, the mean response for the non-white group was 2.13; the white ethnic group were more inclined to agree with vaccination. This association was significant at the $5 \%$ confidence level by the Mann-Whitney U test $(\mathrm{p}=0.006)$. (Table 3 ) Attitude did not differ significantly by social class, gender, parental status or between the three geographical areas surveyed.

Logistic regression modelling explored the effect of age group and ethnicity on attitude (positive attitude to vaccination vs. other). The only significant predictor of not having a positive attitude to vaccination was non- white ethnicity (odds ratio $=2.62,95 \%$ CI 1.16 to 5.92 ).

\section{Other data}

Participants were asked whether they were parents or not but this was not associated with either the knowledge score or attitude response.

A large proportion (70.5\%) of the study population would want the vaccination to be free. The majority 
Table 3: Attitude by ethnicity, social class; age and gender

\begin{tabular}{|c|c|c|c|c|c|c|c|c|c|}
\hline & & \multicolumn{5}{|c|}{ ATTITUDE } & \multirow[b]{2}{*}{ Mean score } & \multirow[b]{2}{*}{ SD } & \multirow[b]{2}{*}{$\mathrm{P}$-value* } \\
\hline & & $\mathbf{I}$ & 2 & 3 & 4 & 5 & & & \\
\hline \multicolumn{10}{|l|}{ Ethnicity } \\
\hline \multirow[t]{2}{*}{ White } & $N$ & 80 & 197 & 15 & 11 & 2 & 1.88 & 0.71 & \\
\hline & $\%$ & 26.2 & 64.6 & 4.9 & 3.6 & 0.7 & & & \\
\hline \multirow[t]{2}{*}{ Non-White } & $\mathrm{N}$ & 21 & 72 & 10 & 10 & 2 & 2.13 & 0.87 & 0.006 \\
\hline & $\%$ & 18.3 & 62.6 & 8.7 & 8.7 & 1.7 & & & \\
\hline \multicolumn{10}{|l|}{ Social Class } \\
\hline \multirow[t]{2}{*}{ Non-manual (I-IIIN) } & $N$ & $4 \mid$ & 123 & 9 & 10 & 2 & 1.97 & 0.77 & \\
\hline & $\%$ & 22.2 & 66.5 & 4.9 & 5.4 & I.I & & & \\
\hline \multirow[t]{2}{*}{ Manual (IIIM-V) } & $\mathrm{N}$ & 60 & 146 & 16 & 11 & 2 & 1.93 & 0.77 & 0.62 \\
\hline & $\%$ & 25.5 & 62.1 & 6.8 & 4.7 & 0.9 & & & \\
\hline \multicolumn{10}{|l|}{ Age } \\
\hline \multirow[t]{2}{*}{$16-24$} & $N$ & 27 & 73 & 7 & 3 & 0 & 1.87 & 0.64 & \\
\hline & $\%$ & 24.5 & 66.4 & 6.4 & 2.7 & 0.0 & & & \\
\hline \multirow[t]{2}{*}{$24-34$} & $\mathrm{~N}$ & 26 & 55 & 4 & 6 & 0 & 1.89 & 0.77 & \\
\hline & $\%$ & 28.6 & 60.4 & 4.4 & 6.6 & 0.0 & & & \\
\hline \multirow[t]{2}{*}{$34-44$} & $\mathrm{~N}$ & 19 & 88 & 11 & 6 & 2 & 2.08 & 0.76 & \\
\hline & $\%$ & 15.1 & 69.8 & 8.7 & 4.8 & 1.6 & & & \\
\hline \multirow[t]{2}{*}{$44-54$} & $\mathrm{~N}$ & 29 & 53 & 3 & 6 & 2 & 1.91 & 0.89 & 0.047 \\
\hline & $\%$ & 31.2 & 57.0 & 3.2 & 6.5 & 2.2 & & & \\
\hline \multicolumn{10}{|l|}{ Gender } \\
\hline \multirow[t]{2}{*}{ Male } & $N$ & 38 & 104 & 11 & 3 & 3 & 1.92 & 0.74 & \\
\hline & $\%$ & 23.9 & 65.4 & 6.9 & 1.9 & 1.9 & & & \\
\hline \multirow[t]{2}{*}{ Female } & $\mathrm{N}$ & 63 & 165 & 14 & 18 & 1 & 1.96 & 0.78 & 0.769 \\
\hline & $\%$ & 24.1 & 63.2 & 5.4 & 6.9 & 0.4 & & & \\
\hline
\end{tabular}

* derived from Kruskall-Wallis test for age; Mann-Whitney $U$ test for other factors.

ATTITUDE:

I = STRONGLY AGREE.

$2=$ AGREE.

$3=$ NO OPINION.

$4=$ DISAGREE.

$5=$ STRONGLY DISAGREE.

Attitude assessed by the question: "Do you think that the introduction of HPV vaccination is a good idea?

(59.3\%) of participants thought that the proposed age group (10-12 years) was acceptable, whereas $34.3 \%$ disagreed.

The majority of study participants believed that boys should be vaccinated as well as girls $(91.2 \%)$.

The majority of participants (83.6\%), both parents and non-parents. reported that they would give consent for their child to have the vaccination.

\section{Discussion}

This study assessed knowledge and attitudes towards HPV vaccination at a time before the UK Government announced its plans for a vaccination programme. Participants aged 16-54 were recruited from three different areas of Birmingham. The majority of participants had little awareness of HPV or HPV vaccination and $81 \%$ had a knowledge score of zero. Nevertheless, after the provision of brief HPV related information messages (Table 4), most (88\%) participants were supportive of HPV vaccination. These findings are in accordance with previous UK-based studies which have demonstrated that people generally know little about HPV, but after the provision of information, most support the introduction of the vaccine [27-30] and re-enforce the need for more educational intervention in order to raise awareness [36].

Although generally low, knowledge scores were higher in the white ethnic group than in the minority ethnic groups and in the non-manual worker group compared to the manual worker group. The white ethnic group were more in favour of HPV vaccination than the minority ethnic group. Both the social class groups were willing to accept HPV vaccination. Stepwise modelling selected social class in preference to the other explanatory variables in predict- 
Table 4: HPV related information provided to participants

- Most cervical cancer is caused by HPV infection.

- HPV is a sexually transmitted infection that can affects both males and females.

- The vaccine protects against HPV infection.

- The government is considering introducing the vaccination.

- Like rubella, the HPV vaccination will be a school based vaccination programme and be given to girls between $10-12$ years.

- Vaccination only effective in people that have not yet been infected with HPV.

ing attitudes towards HPV vaccination. There was a high degree of correlation between ethnicity, social class group and area of residence and each of these factors may be a surrogate for educational attainment.

However, a relatively large proportion of participants (34.3\%) reported concern at the proposed target age group (10-12 years old). Most participants that disagreed with this target group reported that they felt the age group was too young. This survey was undertaken at when the likely age-group for vaccination was believed to be 10-12 years. The recent announcement that the target age group has been increased to 12-13 years may result in increased acceptability. This supports the findings of previous studies in both the USA [37] and UK [38] which have reported less parental support for vaccination in younger age groups.

The small group of the public (6\%) who expressed no opinion towards the vaccination could be due to the fact that they had no or very little knowledge about the vaccination and didn't feel informed enough to form an opinion. Increased awareness and relating to vaccination and the reasons for vaccinating girls at age 12-13 years may address this.

The vast majority (83.6\%) of participants (parents and non-parents) would consent for their child to be vaccinated. This implies a high uptake of the vaccination within the UK population, although reported action does not always reflect actual behaviour.

Limitations of this study include the possibility of sampling bias. As with most cross-sectional surveys, this street survey was only completed by a self-selected group of individuals who may not be representative of the general population. Similarly, the language barrier may have affected uptake ratio in the ethnic minority population, however, the vast majority of the people approached were fluent in English even if it was not their first language. It is probable that those not confident in written English were enabled to participate by the use of a semi-structured interview rather than a postal questionnaire.

Pilot work identified that the initial approach to the public was important; initial reactions often being that the interviewers were attempting to sell a product. Therefore, in the actual survey, all participants were approached by medical students who stated that this was a University research project.

People who failed to take part in the study might differ in their attitudes towards HPV vaccination. Unfortunately, due to the nature of the street survey (purposive sampling) refusal rates were not collected and it was not possible to establish the characteristics of non-participants. It is probable that those with no knowledge of HPV would be less inclined to participate. Knowledge of HPV and the proposed vaccination programme may therefore be overestimated and social desirability bias may mean that reported acceptability of vaccination is over-reported.

This study involved researcher/participant discussion about a Sexually Transmitted Infection (STI). STI's are a sensitive subject especially within different cultures. Questioning people's attitudes towards HPV could be potentially embarrassing for the participant and may have deterred honest responses. To minimise the embarrassment experienced by participants a very simple knowledge score comprising only six questions was used; this may not have been as sensitive as more detailed surveys [25].

This study supports the findings of previous studies in respect to the public's knowledge and attitudes to HPV and the vaccination. The majority of the existing research has assessed the attitudes and knowledge of adolescents and their parents, especially mothers [16-18]. This survey has demonstrated that, in the UK, the attitudes and knowledge of parents and non-parents are similar and it therefore may be possible to generalise from studies focussing on parents to the wider population.

\section{Conclusion}

The study confirms that there is still a lack of information or access to information about HPV and that more needs to be done to raise awareness of HPV and HPV vaccination especially amongst the minority ethnic groups and the lower social classes. Nevertheless, if the vaccination is introduced it appears that a significant number of people would be agreeable to vaccination after the provision of the quite simple messages. 
There is a need for the health care service and other agencies to play a more active role in publicising, educating and informing patients on HPV and potential value of HPV vaccination.

Further work is required to look at the attitudes of health professionals in the UK towards HPV vaccination.

In conclusion, the success of the newly proposed HPV vaccination will depend on public attitudes and acceptance. This study demonstrates that most people state that they would accept the vaccination if it were offered, but more information is needed to increase knowledge. Despite the general view being positive, many people expressed a wish to know more about vaccination. Possible side effects, efficacy, costs and the age group were highlighted as areas of concern.

\section{Competing interests}

The authors declare that they have no competing interests.

\section{Authors' contributions}

CDW wrote the first draft of the introduction and literature review, AG and AS the first draft of the methods and MS, JP and SW undertook the analyses. Abstract, results, discussion and other sections were equally contributed to by all medical students. SW and JP supervised the project. SW had the idea for the study, and is the guarantor. All the authors contributed to the final version of the manuscript and have approved this version.

\section{Acknowledgements}

This work was funded by the University of Birmingham.

\section{References}

I. Mclntyre P: Finding the viral link: the story of Harald Zur Hausen. Cancer World 2005 [http://www.cancerworld.org/Cancer World/getStaticModFile.aspx?id=717].

2. Lowndes CM, Gill OM: Cervical cancer, human papilloma virus and vaccination. $B M / 2005,331: 915-916$.

3. Peckham, Pinedo, Veronesi : Oxford textbook of Oncology. sections 820 Volume 2. Oxford: Oxford University press; 1995.

4. Cavalli F, Hansen HH, Kaye SB: Textbook of Medical Oncology. Martin Dunitz Ltd; 1997.

5. published on the Cancer Research UK Health [http://info.cancerresear chuk.org/news/newsarchive/2007/july//8198873]

6. Koutsky LA, Ault KA, Wheeler CM, Brown DR, Barr E, Alvarez FB, Chiacchierini LM, Jansen KU: A controlled trial of a human papillomavirus type 16 vaccine. The New England Journal of Medicine 2002, 347:|645-5|.

7. Poland GA, Jacobson RM, Koutsky LA, Tamms GM, Railkar R, Smith JF, Bryan JT, Cavanaugh PF, Jansen KU, Barr E: Immunogenicity and reactogenicity of a novel vaccine for human papillomavirus 16: a 2-year randomized controlled clinical trial. Mayo clinic proceedings 2005, 80:60I-6I0.

8. Lehtinen M, Apter D, Dubin G, Kosunen EL, Kyha-Osterlund L, Lunnas T, Luostarinen T, Niemi L, Palmroth J, Petaja T, Rekonen S, Salmivesi S, Siitari-Mattlia M, Svartsjo S, Tuomivaara L, Viikki M, Pukkala E, Paavonen J: Enrolment of 22,000 adolescent women to cancer registry follow up for long term human papillomavirus vaccine efficacy: guarding against guesses. International journal of STD and AIDS 2006, I7(8):517-521.
9. Coombes $R$ : Life saving treatment or giant experiment? $B M J$ 2007, 334:72I-723.

10. Lo B: HPV vaccine and adolescents' sexual activity. BMJ 2006, 332: 1 106-1107.

II. Editorial: Who should be vaccinated against human papillomavirus? The Lancet Infectious Diseases 2006, 6(I):I.

12. published on the Department of Health [http://www.gnn.gov.uk/envi ronment/fullDetail.asp?ReleaselD=293322\&NewsArealD=2].

13. Press release [http://www.gnn.gov.uk/environment/fullDe tail.asp?ReleaselD=325799\&NewsArealD=2\&NavigatedFromDepart ment=False]. Department of Health

14. Editorial: Should HPV vaccines be mandatory for all adolescents? The Lancet 2006, 368:

15. Harper DM, Franco EL, Wheeler C, Ferris DG, Jenkins D, Schuind A, Zahaf T, Innis B, Naud P, De Carvalho NS, Roteli-Martins CM, Teixeira J, Blatter MM, Korn AP, Quint W, Dubin G: GlaxoSmithKline HPV Vaccine Study Group. Efficacy of a bivalent LI virus-like particle vaccine in prevention of infection with human papillomavirus type 16 and 18 in young women: a randomized control trial. The Lancet 2004, 364(9447): 1757-1765.

16. Lowndes CM: Editorial review: Vaccines for cervical cancer. Epidemiol Infect 2006, I34: I-12.

17. Steinbrook R: The Potential of Human Papilllomavirus Vaccines. NEJM 2006, 354: I I09-I I I 2.

18. Zimet GD: Improving adolescent health: Focus on HPV vaccine acceptance. Journal of Adolescent Health 2005, 37(6):SI7-S23.

19. Woodhall SC, Lehtinen M, Verho T, Huhtala $H$, Hokkanen M, Kosunen E: Anticipated Acceptance of HPV Vaccination at the Baseline of Implementation: A Survey of Parental and Adolescent Knowledge and Attitudes in Finland. Journal of Adolescent Health 2007, 40(5):466-469.

20. Dinh TA, Rosenthal SL, Doan ED, Trang T, Pham VH, Tran BD, Tran VD, Bao Phan GA, Chu HKH, Breitkopf CR: Attitudes of Mothers in Da Nang, Vietnam toward a Human Papillomavirus Vaccine. Journal of Adolescent Health 2007, 10:1016.

21. Olshen E, Woods ER, Austin SB, Luskin M, Bauchner H: Parental acceptance of the human papillomavirus vaccine. Journal of Adolescent Health 2005, 36(2): 124.

22. Riedesel JM, Rosenthal SL, Zimet GD, Bernstein DI, Huang B, Lan D, Kahn JA: Family physicians' attitudes about HPV vaccines. Journal of Adolescent Health 2005, 36(2): I24-I25.

23. Zimet GD, Liddon N, Rosenthal SL, Lazcano-Ponce E, Allen B: Psychosocial aspects of vaccine acceptability. Vaccine 2006, 24(Suppl 3):S20I-209.

24. Dell DL, Chen H, Ahmad F, Stewart DF: Knowledge about Human Papillomavirus among adolescents. Obstet Gynecol 2000, 96:653-6.

25. Ogilvie GS, Remple VP, Marra F, McNeil SA, Naus M, Pielak KL, Ehlen TG, Dobson SR, Money DM, Patrick DM: Parental intention to have daughters receive the human papillomavirus vaccine. CMAJ I77(I 2): I506-I2. 2007 Dec 4

26. Friedman AL, Shepeard H: Exploring the knowledge, attitudes and beliefs, and communicating preferences of the general public regarding HPV: findings from CDC focus group research and implications for practice. Health Education Behaviour 2007, 34(3):47I-485.

27. Marlow LAV, Waller J, Wardle J: Parental attitudes to prepubertal HPV vaccination. Vaccine 2007, 25(I I): I945-1952.

28. Waller Marlow L, Wardle J: Public awareness that HPV is a risk factor for cervical cancer. Br J Cancer 2007, 97:691-94.

29. Noakes K, Yarwood J, Salisbury D: Parental response to the introduction of a vaccine against human papilloma virus. Hum Vaccin 2006, 2:243-8.

30. Brabin L, Roberts SA, Farzaneh F, Kitchener HC: Future acceptance of adolescent human papillomavirus vaccination: a survey of parental attitudes. Vaccine 2006, 24:3087-94.

31. Martin D: Health Reporter: Daily Mail. National Newspaper, UK :I I. Saturday May 5, 2007

32. [http://www.statistics.gov.uk].

33. Rose M: Official social classifications in the UK. Guildford: University of Surrey; 1998.

34. Ethnicity coding, London Health Observatory [http:// www.lho.org.uk/viewResource.aspx?id=97/4]

35. [http://www.raosoft.com/samplesize.html]. 
36. Holcomb B, Bailey JM, Crawford K, Ruffin MT: Adults knowledge and behaviours related to human papillomavirus infection. 2004, I 7(I):26-3I.

37. Hopenhayn C, Christian A, Christian WJ, Schoenberg NE: Human Papillomavirus vaccine: Knowledge and attitudes in two Appalachian Kentucky counties. Cancer Causes and Control 2007, I 8(6):627-634.

38. Marlow Laura AV, Waller Jo, Wardle Jane: Sociodemographic predictors of HPV testing and vaccination acceptability: results from a population-representative sample of British women. J Med Screen 2008, I 5(2):91-6. 18573777

\section{Pre-publication history}

The pre-publication history for this paper can be accessed here:

http://www.biomedcentral.com/1471-2458/8/368/pre pub

Publish with Bio Med Central and every scientist can read your work free of charge

"BioMed Central will be the most significant development for disseminating the results of biomedical research in our lifetime. "

Sir Paul Nurse, Cancer Research UK

Your research papers will be:

- available free of charge to the entire biomedical community

- peer reviewed and published immediately upon acceptance

- cited in PubMed and archived on PubMed Central

- yours - you keep the copyright

Submit your manuscript here:

http://www.biomedcentral.com/info/publishing_adv.asp 